\title{
Sound and the Feeling of Presence
}

\author{
Mark Grimshaw-Aagaard \\ Aalborg University \\ Musik, Rendsburggade 14 \\ 9000 Aalborg, Denmark \\ grimshaw@hum.aau.dk
}

\section{ABSTRACT}

As I have written elsewhere, immersion is the holy grail of first-person perspective computer game design (Grimshaw, Lindley, Nacke 2008; Grimshaw 2012). Whether this should be the case is a question I leave to others. Here, what concerns me are other questions such as the relationship of immersion to presence (the term I now prefer to use), what precisely presence is and how is it formed, and what is the role of sound in the formation of presence.

It might seem strange to include a keynote address on the subject of sound at a conference dealing with visualization, but, as someone committed firmly to the idea of perception as fundamentally multimodal, I contend otherwise. Indeed, my conception of sound is that it is an emergent perception formed from the confluence of multimodal sensations and cognitive factors such as reasoning, knowledge, and experience (Grimshaw and Garner 2015). One only has to experience the McGurk Effect to understand that there is a strong relationship between our visual and auditory modalities and that the physics and acoustics conception of sound as a sound wave is somewhat deficient. Similarly, one has only to view a film in a cinema and to analyse that experience to know that the acoustics and psychoacoustics conception of the localization of sound - locating the source of the sound wave - is at odds with our locating the sounds we perceive at the screen and within the wider film universe than at the loudspeakers.

My contention is that we localise sound by locating the emergent perception of sound on objects and events observed in the external world, being guided by experience in doing so. This I use to open up a discussion as to how we model an external reality of sensations as an internal reality of perception, which is the environment in which we are present. If one is to take Slater's description of the process of presence as being "the extent to which the unification of simulated sensory data and perceptual processing produces a coherent 'place' that you are 'in' and in which there may be the potential for you to act" (2003) as reasonable (albeit flawed), and that presence is the feeling of being in that place, then I argue that this unification is made manifest as the environment and that the process of forming this perception is driven by the need to differentiate self from nonself.

Where I disagree with Slater and others is his claim that an increase in the sensory fidelity of virtual worlds is necessary and sufficient for presence to occur. Taking my cue from evolutionary psychologists such as Campbell (1974), I argue that the purpose of our perception (viz. the end result of sensation and cognition) is to distance our selves from external reality by allowing for a perceptual model to be formed (the environment as artefact) that is an abstraction of that, by now, unknowable reality. Perversely, then, we are able to feel present in virtual worlds not because the sensations they produce emulate those sensed from the real world (using primitive and modally constrained technology, this is impossible) but because those sensations comprise a technological abstraction which is then further abstracted as we perceptually model the environment of the virtual world. This reduction through abstraction of the virtual world provides the means and the place in which to be present.

\section{BIOGRAPHY}

Mark Grimshaw-Aagaard is the Obel Professor of Music at Aalborg University, Denmark. He has published widely across subjects as diverse as sound, biofeedback in computer games, virtuality, the Uncanny Valley, and IT systems and also writes free, open source software for virtual research environments (WIKINDX). Mark is series editor for the Palgrave Macmillan series Studies in Sound, and his books include the anthologies Game Sound Technology \& Player Interaction (IGI Global 2011) and The Oxford Handbook of 
Virtuality (Oxford University Press 2014), and, with co-author Tom Garner, a monograph entitled Sonic Virtuality (Oxford University Press 2015). A twovolume co-edited anthology, The Oxford Handbook of Sound \& Imagination, is due in 2019 from Oxford University Press as is the co-authored The Recording, Mixing, \& Mastering Reference Handbook.

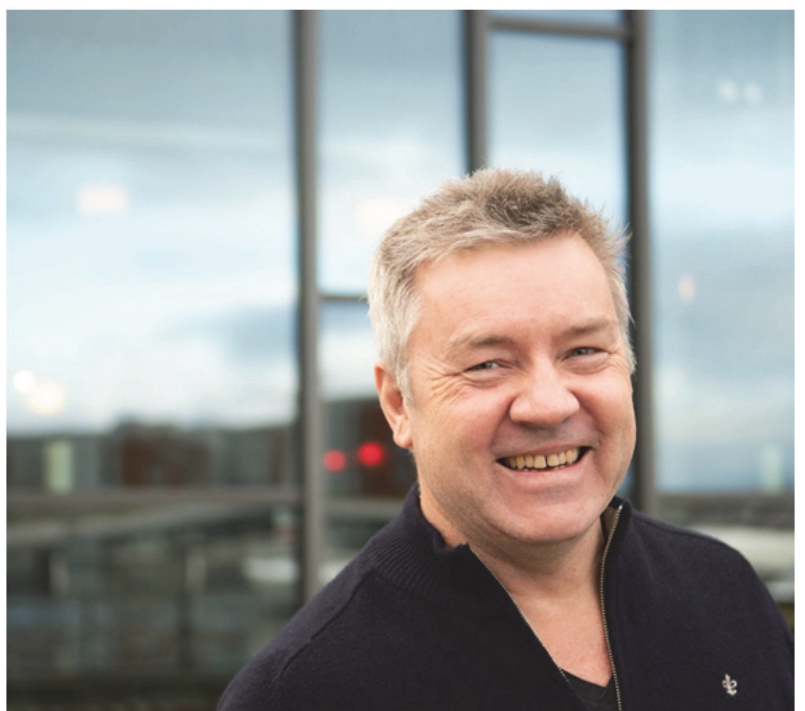

Figure 1: At EVA London 2019, Mark GrimshawAagaard will present his keynote 'Sound and the Feeling of Presence'.

\section{REFERENCES}

Campbell, D. T. (1974) Evolutionary epistemology. In P. A. Schilpp (ed), The Philosophy of Karl Popper Vol. XIV Book 1, (413-463). Open Court, La Salle, Illinois.

Grimshaw, M. (2012) Sound and player immersion in digital games. In T. Pinch \& K. Bijsterveld (eds), The Oxford Handbook of Sound Studies. Oxford University Press, New York.

Grimshaw, M. and Garner, T. A. (2015) Sonic virtuality: Sound as emergent perception. Oxford University Press, New York.

Grimshaw, M., Lindley, C. A. and Nacke, L. (2008). Sound and immersion in the first-person shooter: Mixed measurement of the player's sonic experience. Audio Mostly 2008, Piteå, Sweden, October 22-23.

Slater, M. (2003) A note on presence terminology. Presence Connect, 3(3). 